\title{
In vivo Effects of Abused 'Bath Salt' Constituent 3,4-methylenedioxypyrovalerone (MDPV) in Mice: Drug Discrimination, Thermoregulation, and Locomotor Activity
}

\author{
William E Fantegrossi*,', Brenda M Gannon', Sarah M Zimmerman' and Kenner C Rice ${ }^{2}$ \\ 'Department of Pharmacology and Toxicology, College of Medicine, University of Arkansas for Medical Sciences, Little Rock, AR, USA; ${ }^{2}$ Drug \\ Design and Synthesis Section, Chemical Biology Research Branch, NIDA and NIAAA, Bethesda, MD, USA
}

\begin{abstract}
In recent years, synthetic analogues of naturally occurring cathinone have emerged as psychostimulant-like drugs of abuse in commercial 'bath salt' preparations. 3,4-Methylenedioxypyrovalerone (MDPV) is a common constituent of these illicit products, and its structural similarities to the more well-known drugs of abuse 3,4-methylenedioxymethamphetamine (MDMA), and methamphetamine (METH) suggest that it may have similar in vivo effects to these substances. In these studies, adult male NIH Swiss mice were trained to discriminate $0.3 \mathrm{mg} / \mathrm{kg}$ MDPV from saline, and the interoceptive effects of a range of substitution doses of MDPV, MDMA, and METH were then assessed. In separate groups of mice, surgically implanted radiotelemetry probes simultaneously monitored thermoregulatory and locomotor responses to various doses of MDPV and MDMA, as a function of ambient temperature. We found that mice reliably discriminated the MDPV training dose from saline and that cumulative doses of MDPV, MDMA, and METH fully substituted for the MDPV training stimulus. All three drugs had similar $\mathrm{ED}_{50}$ values in this procedure. Stimulation of motor activity was observed following administration of a wide range of MDPV doses $(1-30 \mathrm{mg} / \mathrm{kg}$ ), and the warm ambient temperature potentiated motor activity and elicited profound stereotypy and self-injurious behavior at $30 \mathrm{mg} / \mathrm{kg}$. In contrast, MDPV-induced hyperthermic effects were observed in only the warm ambient environment. This pattern of effects is in sharp contrast to MDMA, where ambient temperature interacts with thermoregulation, but not locomotor activity. These studies suggest that although the interoceptive effects of MDPV are similar to those of MDMA and METH, direct effects on thermoregulatory processes and locomotor activity are likely mediated by different mechanisms than those of MDMA.

Neuropsychopharmacology (20I3) 38, 563-573; doi:I0.I038/npp.2012.233; published online 5 December 2012
\end{abstract}

Keywords: designer drug; cathinone; behavior; thermoregulation; locomotor activity

\section{INTRODUCTION}

A variety of ring- and side-chain-substituted analogues ( $\beta$ ketophenethylamines) of the plant-derived cathinone have recently emerged as drugs of abuse, typically marketed on the internet and at head shops as 'research chemicals,' 'plant food,' or, most commonly, 'bath salts.' The American Association of Poison Control Centers reported that, from 2010 to 31 July 2012, 8520 calls relating to human exposures to 'bath salts' were processed (AAPCC, 2012). Similarly, the Drug Enforcement Administration System to Retrieve Information from Drug Evidence received a total of 76857 drugs in 2010, 35 of which were synthetic cathinones-most commonly identified as 3,4-methylenedioxypyrovalerone (MDPV; 27 reports or 77\%) (US DEA, 2011). The data

*Correspondence: Dr WE Fantegrossi, Department of Pharmacology and Toxicology, College of Medicine, University of Arkansas for Medical Sciences, 430I West Markham Street, Mail Slot no. 638, Little Rock, AR 72205, USA, Tel: + | $50 \mid 6868883$, Fax: + | $50 \mid 6868970$, E-mail:WEFantegrossi@uams.edu

Received I5 September 2012; revised 3 November 2012; accepted 5 November 2012; accepted article preview online 8 November 2012 compiled from law enforcement and poison control centers thus suggest that the abuse of synthetic cathinones appears to be continuing to spread and proliferate, and sensationalistic media reports of extremely bizarre behaviors in those suspected to have used 'bath salts' has fueled scientific and regulatory interest in these compounds.

Some of the synthetic cathinones have thus far remained uncontrolled, but many of the more common compounds, including MDPV, have been regulated as Schedule I controlled substances in the United States (Leonhart, 2011). In addition to MDPV, numerous other cathinone analogues, including 4-methylmethcathinone (mephedrone, 4-MMC) and 3,4-methylenedioxymethcathinone (methylone) have been identified in 'bath salt' preparations (Ross et al, 2011; Spiller et al, 2011), but MDPV remains the drug most commonly detected by Emergency Department screens on blood and urine samples from those experiencing untoward effects after exposure to these commercial products in the United States (Kyle et al, 2011; Spiller et al, 2011; Borek and Holstege, 2012; Murray et al, 2012). Despite these indications that MDPV may be a growing public health concern, it remains the case that scant information is 
available regarding its mechanism of action or in vivo effects. In this regard, the structurally similar pyrovalerone has been shown to stimulate spontaneous locomotor activity in rodents (Fauquet et al, 1976; Vaugeois et al, 1993) and to induce stimulant-like actions in humans (Holliday et al, 1964; Goldberg et al, 1973). More recently, it was demonstrated that pyrovalerone has cocaine-like effects at dopamine reuptake transporters (Heron et al, 1994; Tidjane Corera et al, 2001; Meltzer et al, 2006) and that these effects are also apparent in MDPV itself (Baumann et al, 2012b; Simmler et al, 2012). In an early study, orally administered MDPV was demonstrated to induce locomotor-stimulant effects in mice (Fuwa et al, 2007), and this year, studies have reported that MDPV elicits locomotor stimulation (Huang et al, 2012) and possesses reinforcing effects in rats (Watterson et al, 2012). All of these findings are consistent with a psychostimulant-like profile of action for this compound.

In this regard, MDPV bears some structural similarities with the more well-known phenethylamine psychostimulants 3,4-methylenedioxymethamphetamine (MDMA) and methamphetamine (METH) (Figure 1), suggesting that it may possess behavioral and physiological effects similar to these two substances. Importantly, in the mouse, MDMA is much more of a dopaminergic agent than it appears to be in other species, eliciting neurochemical and behavioral effects similar to those of METH after both acute and chronic treatment (O'Callaghan and Miller, 1994; Mann et al, 1997; Itzhak and Achat-Mendes, 2004; Itzhak et al, 2004; Fantegrossi et al, 2008; Panas et al, 2010; Granado et al, 2011; Murnane et al, 2012). These observed similarities between the effects of MDMA and METH are likely because of similar neuropharmacology of these compounds in the mouse. Thus, understanding whether or not MDPV elicits effects similar to those of MDMA and METH in the mouse is critical to formulating appropriate public health responses to this emerging drug of abuse. Therefore, in these studies, we used drug discrimination to compare the interoceptive effects of MDPV with those of MDMA and METH in mice. As negative controls, we also substituted the synthetic cannabinoid JWH-018 (1-pentyl-3-(1-naphthoyl)indole)) and the opioid morphine. In addition, we studied the time course of discriminative stimulus effects of MDPV after a single bolus dose. We also used simultaneous radiotelemetry of core temperature and locomotor activity to study the effects of MDPV on these two end points. Of particular interest was an evaluation of the potential of ambient temperature to have an impact on MDPV effects. Previous studies have shown that the thermoregulatory effects of MDMA depend critically on ambient temperature, with the same doses of MDMA eliciting hypothermia at low ambient temperatures, and hyperthermia at high ambient temperatures (Dafters, 1994; Malberg and Seiden, 1998). Importantly, the locomotor-stimulant effects of MDMA are
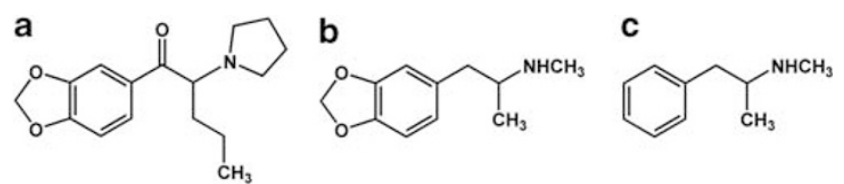

Figure I Chemical structures of the drugs used in these studies. (a) MDPV, (b) MDMA, and (c) METH. not affected by ambient temperature (Dafters, 1994; O'Shea et al, 2005). Similarly, the structurally similar synthetic cathinone 4-MMC has recently been shown to exhibit thermoregulatory and locomotor effects distinct from those of MDMA or METH (Wright et al, 2012), suggesting that an evaluation of the role of ambient temperature in MDPV effects is warranted.

\section{MATERIALS AND METHODS}

\section{Animals}

All studies were carried out in accordance with the Guide for Care and Use of Laboratory Animals as adopted and promulgated by the National Institutes of Health. Experimental protocols were approved by the Institutional Animal Care and Use Committee at the University of Arkansas for Medical Sciences. Male NIH Swiss mice (Harlan Sprague Dawley) weighing $20-25 \mathrm{~g}$ on delivery were housed three animals per cage $\left(15.24 \times 25.40 \times 12.70 \mathrm{~cm}^{3}\right)$ in a temperature-controlled room in an Association for Assessment and Accreditation of Laboratory Animal Care-accredited animal facility. Room conditions were maintained at $22 \pm 2{ }^{\circ} \mathrm{C}$ and $45-50 \%$ humidity, with lights set to a 12 -h light/dark cycle. Animals were fed Lab Diet rodent chow (Laboratory Rodent Diet no. 5001, PMI Feeds, St Louis, MO) and, with the exception of mice used in drug-discrimination experiments, were fed ad libitum until immediately before testing. Mice used in drug-discrimination experiments were food restricted for the duration of all studies, and their weights were maintained at approximately $30 \mathrm{~g}$ with supplemental feedings after daily behavioral sessions. All test conditions used groups of five or six mice, and all mice were drug naive (with the exception of surgical anesthetics) before testing.

\section{Procedures}

Drug discrimination. Mice $(n=6)$ were trained to discriminate $0.3 \mathrm{mg} / \mathrm{kg}$ MDPV from saline in standard operant chambers for mice that were individually enclosed in larger lightproof Malaguard sound-attenuating cubicles (MED Associates, St Albans, VT). The side wall of each chamber used in these studies was equipped with an aperture through which liquid reinforcement was delivered, driven by a dipper mounted outside the chamber but within the cubicle. The reinforcement aperture was centered between two retractable levers and contained an amber stimulus light, which was illuminated during reinforcer delivery.

Lever training: Mice were trained 5 days per week to respond in two-lever operant conditioning boxes, reinforced by $2 \mathrm{~s}$ of access to a palatable liquid reinforcer (approximately $0.02 \mathrm{ml}$ evaporated milk diluted $1: 1$ with water). Upon completion of the response requirement on either lever, that lever was retracted and reinforcement was delivered. After a brief (10 s) time-out (TO), mice were required to complete the response requirement on the remaining lever. Both levers were reintroduced into the chamber after the 10-s TO. In this manner, mice received equivalent reinforcement from each lever, and no subsequent biases for one lever or the other were noted. Animals were initially maintained on a fixed ratio 1 (FR 1) schedule 
of reinforcement in sessions lasting $60 \mathrm{~min}$ or until 60 reinforcers had been earned (whichever came first.) The FR value increased by one increment every 20th reinforcer earned within a given session, and the FR value achieved was carried over between sessions until mice were responding under an FR 10. This segment of the training was complete when mice reached an FR 10 and earned all 60 available reinforcers for at least 5 consecutive days.

Discrimination training: Mice were trained during daily $30 \mathrm{~min}$ sessions to discriminate their training dose $(0.3 \mathrm{mg} /$ $\mathrm{kg}$ MDPV) from saline vehicle. When animals were injected with the training dose, responses on the drug lever (DL) produced the reinforcer. When administered a saline injection, responses on the saline lever (SL) were reinforced. Injections were administered intraperitoneally $10 \mathrm{~min}$ before extension of the response levers, signaling the start of the behavioral session. During discrimination training, responses on the incorrect lever reset the $\mathrm{FR}$ on the injection-appropriate lever, but had no other programmed consequences. Completion of the FR 10 on the injectionappropriate lever was reinforced. Percent drug-appropriate responding was calculated as the number of responses emitted on the injection-appropriate lever divided by the total number of responses on both levers, multiplied by 100 . Training was composed of an alternating schedule of drug or saline injection. Subjects were switched from saline to drug or vice versa for the next day of training if they achieved a criterion of $>85 \%$ injection-appropriate responding. Drug-induced stimulus control was assumed to be present when, in five consecutive sessions, animals achieved $80 \%$ or better injection-appropriate responding.

Substitution testing: After stimulus control was established with the training drug, tests were conducted once or twice per week in each animal so long as performance did not fall below the criterion level of $80 \%$ injection-appropriate responding in any one of the previous three training sessions. Approximately half of the test sessions were conducted the day after saline training sessions with the remainder following drug training sessions. During test sessions, a multiple-component cumulative dosing procedure was used, and no responses were reinforced. Each component was terminated after the emission of 10 responses on either lever. Mice were then removed from the chamber, administered the next cumulative dose, and returned to the chamber. Ten minutes later, levers were reextended into the experimental space. In this manner, four doses of drug could be tested in a single session, over approximately $40 \mathrm{~min}$. The distribution of responses between the two levers was expressed as a percentage of total responses emitted on the drug-appropriate lever. Response rate was calculated for each session by dividing the total number of responses emitted on both levers by the elapsed time before 10 responses on either lever. Two 'all saline' substitution sessions were conducted to ensure discriminative performance would be maintained across multiple components, and to obtain baseline response rates against which to compare the effects of MDPV, MDMA, and METH, as well as the negative control compounds JWH018 and morphine.

Complete generalization of a training drug to a test drug is said to be present when (a) a mean of $\geqslant 80 \%$ of all test responses occurs on the drug-appropriate lever and (b) there is a statistically significant difference between the response distributions of the test drug and saline control sessions. An intermediate degree of generalization is defined as being present when response distributions after a test drug are $<80 \%$ drug-appropriate lever and are significantly different from saline control sessions. Finally, when the response distribution after a test drug is not statistically different from that in saline control sessions, an absence of generalization of the training drug to the test drug is assumed. Failure to complete an FR 10 on either lever within $10 \mathrm{~min}$ terminated the sessions and indicated disruption of schedule-controlled behavior. In this manner, saline, MDPV, MDMA, METH, and negative control drugs JWH-018 and morphine were tested in all mice on at least two occasions.

Time-course experiments were performed in a manner similar to that previously described (Fantegrossi et al, 2009). Briefly, mice were injected with a single bolus dose of MDPV, then placed in the operant chamber. Ten minutes later, levers were extended into the experimental space, and would remain there until 10 responses were emitted on one lever or the other, with the constraint that this response requirement must be met within $10 \mathrm{~min}$. No responses were reinforced, and levers were retracted for $10 \mathrm{~min}$ before being reintroduced for another component identical to that previously described. In this manner, the time course of discriminative stimulus effects could be assessed at 10-min intervals, over $80 \mathrm{~min}$.

Radiotelemetry of thermoregulation and locomotor activity. Once anesthetized with inhaled isoflurane, the abdominal area of each mouse was shaved and sanitized with iodine swabs. A rostral-caudal cut approximately $1.5 \mathrm{~cm}$ in length was made with sterile skin scissors, providing access to the intraperitoneal cavity. A cylindrical glass-encapsulated radiotelemetry probe (model ER-4000 E-Mitter; Mini Mitter, Bend, OR) was then inserted, and the incision was closed using absorbable 5-0 chromic gut suture material. Surgeries were carried out at least 7 days before initiation of experimental conditions, allowing time for incisions to heal and for mice to recover normal body weights. Following surgery, all implanted mice were individually housed in $15.24 \times 25.40 \times 12.70 \mathrm{~cm}^{3}$ cages for the duration of all telemetry experiments.

Implanted transmitters produced activity- and temperature-modulated signals that were sent to a receiver (model ER-4000 Receiver; Mini Mitter) underneath each cage. These receivers were situated inside standard light- and sound-attenuating chambers (Model ENV-022M; Med Associates) to minimize environmental variability during tests. Every $5 \mathrm{~min}$, the computer collected two data updates from the probes-core temperature (in ${ }^{\circ} \mathrm{C}$ ) on one channel and locomotor counts on the other. Each chamber was equipped with a house light (to establish a photoperiod), an exhaust fan, and a warm air heater (to increase the ambient temperature). In this regard, the HVAC system of the room was sufficient to maintain the desired 'cool' ambient temperature of $20^{\circ} \mathrm{C}$, but the heaters attached to each chamber were used to maintain the 'warm' condition at $28{ }^{\circ} \mathrm{C}$. Ambient temperatures were monitored every $5 \mathrm{~min}$ by data loggers sited within the chambers (Lascar EL-USB1; MicroDAQ, Contoocook, NH), and could be read at a 
glance on digital thermometers attached to each chamber. The mean temperature recorded by the data loggers during the 'cool' condition was $20.16^{\circ} \mathrm{C}$ (with a low of $18.88^{\circ} \mathrm{C}$ and a high of $21.73^{\circ} \mathrm{C}$ ), whereas the mean temperature recorded during the 'warm' condition was $27.96^{\circ} \mathrm{C}$ (with a low of $26.61{ }^{\circ} \mathrm{C}$ and a high of $29.53^{\circ} \mathrm{C}$ ) (see Supplementary Figure 1). After at least $60 \mathrm{~min}$ of baseline data collection, mice ( $n=5$ or 6$)$ were removed from the chambers, injected with test compound (or saline), returned to the home cage, and then returned to the chambers for $24 \mathrm{~h}$ of data collection.

\section{Data Analysis}

Graphical presentation of all drug discrimination and locomotor activity data depict mean \pm SEM. For core temperature dose-effect data (Figure 5), error bars have been eliminated in order to maximize clarity of thermoregulatory responses, but SEM variability are presented in comparisons between MDPV and MDMA at both ambient temperatures (Figure 6). Drug-discrimination data are expressed as percent drug-appropriate responding, which is the number of responses emitted on the drug-appropriate lever as a percentage of the total number of responses emitted. Subjects failing to emit 10 responses within 5 min of lever extension were deemed to be behaviorally disrupted and were not considered in the calculation of the percent drug-appropriate responding. Generalization was said to occur if $\geqslant 80 \%$ of the responses were on the drugappropriate lever, and the group mean was significantly different (via Kruskal-Wallis one-way analysis of variance (ANOVA) on ranks, followed by pairwise comparisons using the Dunn's method) from saline. Nonlinear regression analysis with a variable-slope sigmoidal dose-response curve was used to calculate the dose that elicited 50\% MDPV-appropriate responding $\left(\mathrm{ED}_{50}\right.$; with a set range of 0-100\%) for each individual animal using Graphpad Prism 4 (La Jolla, CA). These $\mathrm{ED}_{50}$ values were averaged for each drug ( $n=6$ for all drugs) to determine mean $\mathrm{ED}_{50} \pm$ SEM.
Although $24 \mathrm{~h}$ of core temperature and locomotor data were collected following all injections, figures are truncated at times between 6 and $10 \mathrm{~h}$ as measures had returned to control values. Core temperature data are presented as 5 min means, whereas locomotor activity data have been binned in $30 \mathrm{~min}$ averages.

\section{Drugs}

Racemic MDPV was synthesized in the Laboratory of Medicinal Chemistry at NIDA by one of us (KCR). Morphine, racemic MDMA, and racemic METH were obtained from the NIDA Drug Supply Program. JWH-018 was synthesized in the Department of Medicinal Chemistry at the University of Kansas and was provided as a generous gift by Thomas E Prisinzano, PhD. MDPV, MDMA, METH, and morphine were dissolved in $0.9 \%$ physiological saline, whereas JWH-018 was dissolved in a solution of $7.8 \%$ Tween 80 and $92.2 \%$ sterile water. Injections were administered intraperitoneally at a volume of $0.1 \mathrm{cc} / 10 \mathrm{~g}$. Saline vehicle and all other experimental supplies were obtained from standard commercial sources.

\section{RESULTS}

\section{Drug Discrimination}

Mice reliably learned to discriminate $0.3 \mathrm{mg} / \mathrm{kg}$ MDPV (black circle) from saline (white square) (Figure 2, left panel.) When saline was administered in training sessions, mice primarily responded on the SL. Similarly, when the training dose was administered, mice responded almost exclusively on the MDPV lever. Response rates during substitution tests were lower than those observed during training sessions, and, in sessions where saline was administered in all four components, generally decreased across the session, with rates between approximately 1.1 (in component 1) and 0.5 (in component 4) responses per second being observed (white squares, Figure 2, right
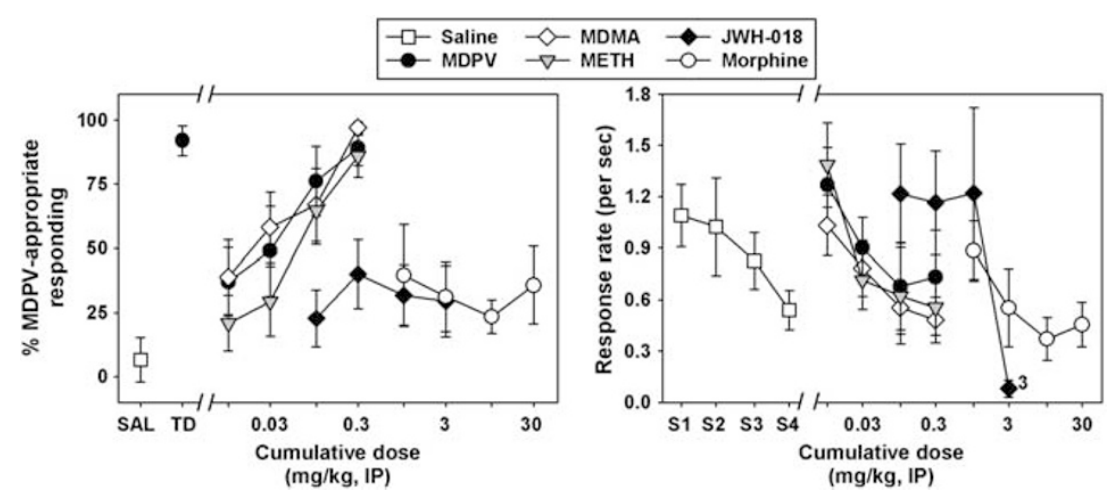

Figure 2 Left panel_discriminative stimulus effects of MDPV (black circles), MDMA (white diamonds), METH (gray triangles), JWH-0I8 (black diamonds), and morphine (white circles) in NIH Swiss mice trained to discriminate $0.3 \mathrm{mg} / \mathrm{kg}$ MDPV from saline (white square.) Abscissa: 'SAL' represents data following training injections of saline, whereas 'TD' represents data following administration of the MDPV training dose. Numbers refer to cumulative doses of drugs during substitution sessions, expressed as $\mathrm{mg} / \mathrm{kg}$ on a log scale. Ordinate: percent of total responses emitted on the MDPV-appropriate lever. Right panel— response rates engendered during substitution sessions by multiple administrations of saline (white squares), MDPV (black circles), MDMA (white diamonds), METH (gray triangles), JWH-0I8 (black diamonds), or morphine (white circles). Numerals adjacent to points indicate the number of animals that failed to respond at this dose. Abscissa: 'SI-S4' represent the four discrete saline injections administered in all components of a substitution session. Numbers refer to cumulative doses of drugs during substitution sessions, expressed as $\mathrm{mg} / \mathrm{kg}$ on a log scale. Ordinate: response rates, expressed as lever presses per second. 
panel). During these 'all saline' substitution tests, mean MDPV lever responses ranged from $6.43 \pm 4.12$ to $22.38 \pm 14.80 \%$, and did not systematically increase or decrease as the session proceeded (data not shown). During substitution tests with cumulative doses of MDPV (black circles, Figure 2, left panel), dose-dependent and full substitution for the training dose was observed, with $>80 \%$ of the total responses emitted on the DL at a cumulative dose of $0.3 \mathrm{mg} / \mathrm{kg}$. This highest tested dose of MDPV was significantly different from discriminative responding elicited by saline $(Q=4.156, P<0.05)$. The interpolated $\mathrm{ED}_{50}$ for cumulative MDPV was $0.03 \pm 0.01 \mathrm{mg} /$ $\mathrm{kg}$, and response rates engendered by cumulative MDPV generally decreased across the session, in a manner similar to that observed with successive saline injections (black circles, Figure 2, right panel).

Treatment with MDMA elicited a dose-dependent and full substitution for the MDPV training dose (white diamonds, Figure 2, left panel), with near exclusive choice of the DL at a cumulative dose of $0.3 \mathrm{mg} / \mathrm{kg}$. This highest tested dose of MDMA was significantly different from discriminative responding elicited by saline $(\mathrm{Q}=4.745, P<0.05)$. The interpolated $\mathrm{ED}_{50}$ for cumulative MDMA was identical to that of MDPV: $0.03 \pm 0.01 \mathrm{mg} / \mathrm{kg}$. Substitution doses of MDMA dose-dependently suppressed response rates (white diamonds, Figure 2, right panel). Similarly, cumulative injections of METH also engendered dose-dependent and full substitution in this assay (gray triangles, Figure 2, left panel), with $>80 \%$ of the total responses emitted on the DL at a cumulative dose of $0.3 \mathrm{mg} / \mathrm{kg}$. This highest tested dose of METH was significantly different from discriminative responding elicited by saline $(Q=3.732, P<0.05)$. The interpolated $\mathrm{ED}_{50}$ for cumulative $\mathrm{METH}$ was $0.08 \pm 0.03 \mathrm{mg} /$ $\mathrm{kg}$, and METH dose-dependently suppressed response rates (gray triangles, Figure 2, right panel). Substitutions with the negative control compounds JWH-018 (black diamonds, Figure 2) and morphine (white circles, Figure 2) resulted primarily in responding on the SL, up to doses that suppressed response rates.

The discriminative stimulus effects of MDPV were doseand time dependent (Figure 3, left panel). Following a bolus injection of $0.1 \mathrm{mg} / \mathrm{kg}$ MDPV (gray circles, Figure 3), responding was primarily on the saline-associated lever at $10 \mathrm{~min}$ after drug administration, but increased to a peak of $64.97 \pm 17.56 \%$ of responses emitted on the MDPV-associated lever at $30 \mathrm{~min}$, then systematically declined to saline- like levels by $50 \mathrm{~min}$ after injection. Injection of $0.3 \mathrm{mg} / \mathrm{kg}$ (black circles, Figure 3) engendered a similar pattern to that observed with the lower dose for the first $30 \mathrm{~min}$ after injection, but MDPV lever responding continued to increase to a maximum of $86.84 \pm 10.74 \%$ at $50 \mathrm{~min}$, then decreased to saline-like levels by $60 \mathrm{~min}$ after injection. Administration of a bolus $1.0 \mathrm{mg} / \mathrm{kg}$ dose of MDPV (white circles, Figure 3) resulted in substantial MDPV lever selection within $10 \mathrm{~min}$ of injection, peaking at a maximum of $89.04 \pm 8.00 \%$ at $30 \mathrm{~min}$, and finally declining to saline-like levels at $80 \mathrm{~min}$ post administration. Response rates (Figure 3, right panel) were relatively stable across repeated testing for a given bolus dose of MDPV, with no systematic increases or decreases observed from component to component.

\section{Radiotelemetry}

MDPV had a main effect on locomotor activity in mice at all doses tested, regardless of ambient temperature (Figure 4, left panel, $H=34.261, P<0.001)$. Interestingly, at an ambient temperature of $20^{\circ} \mathrm{C}$, the locomotor-stimulant effects of MDPV were not dose dependent across the dose range studied. In contrast, at $28{ }^{\circ} \mathrm{C}, \mathrm{MDPV}$ generated a more typical biphasic dose-response curve, and at $10 \mathrm{mg} / \mathrm{kg}$, the locomotor response was significantly greater $(\mathrm{F}=8.671$, $P<0.05)$ than that observed when this same dose was administered in the cool ambient environment. This apparent increase in motor activity was not due to a prolonged duration of drug action at $28^{\circ} \mathrm{C}$, but rather by an induction of greater motor activation at all time points (Figure 4, right panel). At the highest tested dose of MDPV (30 mg/kg), significant focused stereotypy was observed at $28{ }^{\circ} \mathrm{C}$, but not at $20^{\circ} \mathrm{C}$. Furthermore, four (of six) mice treated with $30 \mathrm{mg} / \mathrm{kg}$ MDPV at the high ambient temperature engaged in skin-picking and self-biting, which drew blood, and, in accordance with our IACUC approval, were removed from the study and euthanized. No signs of selfinjurious behavior were observed at any dose of MDPV administered at $20^{\circ} \mathrm{C}$. In contrast to MDPV, the effects of MDMA on locomotor activity have not previously been shown to depend on ambient temperature, and in these present experiments, $10 \mathrm{mg} / \mathrm{kg}$ MDMA elicited essentially identical locomotor responses at $20^{\circ} \mathrm{C}$ (Figure 5, black circles) and $28^{\circ} \mathrm{C}$ (Figure 5, white circles) across the time points we were able to study (see below).
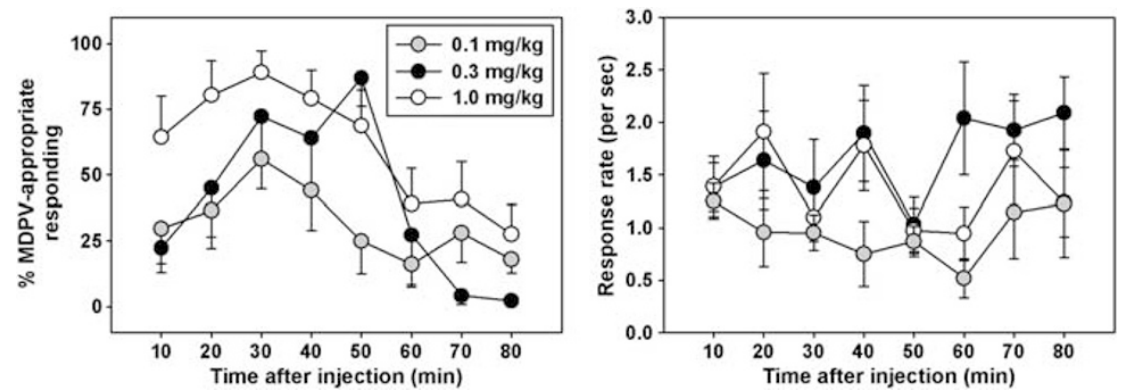

Figure 3 Left panel—time course of discriminative stimulus effects of various bolus doses of MDPV in NIH Swiss mice trained to discriminate 0.3 mg/kg MDPV from saline. Abscissa: time after injection, in minutes. Ordinate: percent of total responses emitted on the MDPV-appropriate lever. Right panelresponse rates across the time course engendered by bolus injection of various doses of MDPV. Abscissa: time after injection, in minutes. Ordinate: response rates, expressed as lever presses per second. 

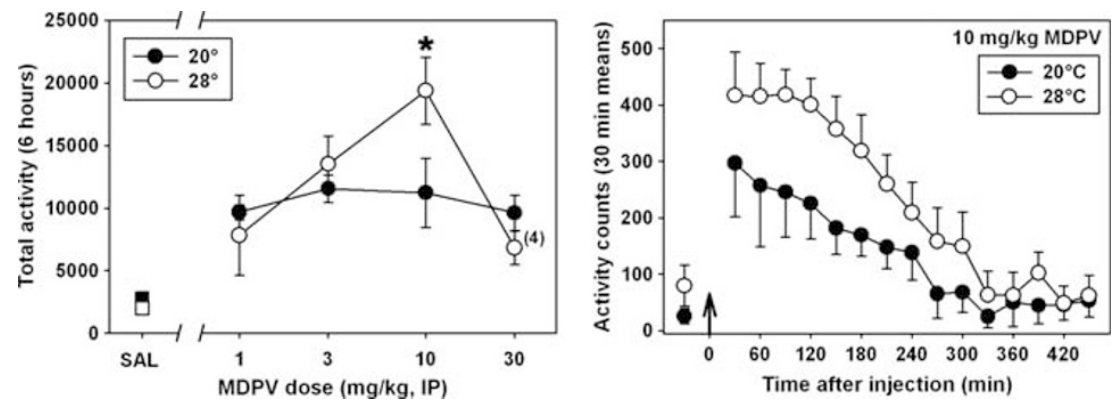

Figure 4 Left panel-locomotor activity elicited by administration of saline (squares) or various doses of MDPV (circles) in a cool (filled) or warm (unfilled) ambient environment. Abscissa: 'SAL' represents saline control data at both ambient temperatures. Numbers refer to doses of MDPV, in separate groups of animals, expressed as $\mathrm{mg} / \mathrm{kg}$ on a log scale. Ordinate: mean total activity recorded over $6 \mathrm{~h}$ post injection, via radiotelemetry. The '(4)' adjacent to the data point for $30 \mathrm{mg} / \mathrm{kg}$ MDPV administered in the warm ambient environment denotes that four (of six) mice were killed at various time points after injection when self-injurious behavior was observed. Asterisks indicate significant differences between doses administered at ambient temperatures of 20 and $28^{\circ} \mathrm{C}$. Right panel—-time course of locomotor stimulation following administration of $10 \mathrm{mg} / \mathrm{kg}$ MDPV in a cool (black circles) or warm (white circles) ambient environment. Abscissa: points to the left of the up arrow denote baseline data before injection, presented as the mean activity observed over I h. Numbers refer to time, in minutes, following MDPV administration. Ordinate: mean activity counts calculated in 30 min bins.

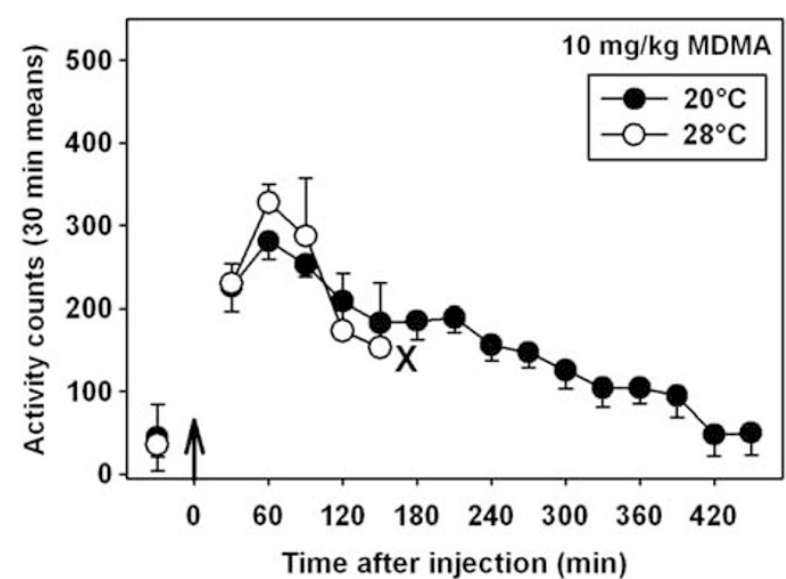

Figure 5 Locomotor activity elicited by administration of $10 \mathrm{mg} / \mathrm{kg}$ MDMA at an ambient temperature of $20^{\circ} \mathrm{C}$ (black circles) or $28^{\circ} \mathrm{C}$ (white circles). The ' $X$ ' adjacent to the last data point obtained following administration of MDMA in the warm ambient environment denotes the approximate time that all mice were removed from the chambers and euthanized, in accordance with our IACUC protocol. Abscissa: points to the left of the up arrow denote baseline data before injection, presented as the mean activity observed over I h. Numbers refer to time, in minutes, following MDMA administration. Ordinate: mean activity counts calculated in 30 min bins.

At an ambient temperature of $20^{\circ} \mathrm{C}$, mice treated with saline maintained core temperatures between approximately 36 and $38^{\circ} \mathrm{C}$ (shaded region, Figure 6, left panel). Similar results were obtained at an ambient temperature of $28^{\circ} \mathrm{C}$, where mice cycled between approximately 36 and $38^{\circ} \mathrm{C}$, over $24 \mathrm{~h}$ after saline administration (shaded region, Figure 6, right panel). Thus, the ambient temperature did not appear to have an impact on normal thermoregulation in these subjects. Doses of MDPV from $1-30 \mathrm{mg} / \mathrm{kg}$ increased core temperature in mice at the $20-^{\circ} \mathrm{C}$ ambient temperature (Figure 6, left panel), but not more so than saline injection. In contrast, at $28^{\circ} \mathrm{C}$ (Figure 6, right panel), doses of 3,10 , and $30 \mathrm{mg} / \mathrm{kg} \mathrm{MDPV}$ pushed temperatures outside the normal thermoregulatory range. These hyperthermic effects were not dose dependent at the cool ambient temperature (filled circles, Figure 7), but the mean maximum temperature recorded appeared to increase with dose in the warm ambient environment (open circles, Figure 7). Unfortunately, intersubject variability was high, and with the relatively small group sizes in these studies, we lacked the statistical power to detect significant differences at any condition (the power of the performed ANOVA was 0.41 , which is below the 0.80 power desired to make appropriate statistical comparisons). Similarly, consistent with previous studies, $10 \mathrm{mg} / \mathrm{kg}$ MDMA elicited mild hypothermic effects at $20^{\circ} \mathrm{C}$ (white diamonds, Figure 8, left panel) and severe hyperthermic effects at $28^{\circ} \mathrm{C}$ (white diamonds, Figure 8, right panel). Indeed, all mice in this group met our IACUC protocol threshold for removal from the study (core temperatures over $41^{\circ} \mathrm{C}$ for $30 \mathrm{~min}$ ) and were immediately euthanized.

\section{DISCUSSION}

The studies reported here include the first evaluations of the interoceptive effects of MDPV, a primary psychoactive component of commercial 'bath salt' preparations (Ross et al, 2011; Spiller et al, 2011), in comparison with those of MDMA and METH in the mouse. We found that MDPV was readily trained as a discriminative stimulus, and that the discrimination was relatively pharmacologically specific, as substitution tests with the synthetic cannabinoid JWH-018 and the opioid morphine failed to engender any significant MDPV-like responding up to doses that suppressed leverpressing behavior. On the other hand, the structurally related psychostimulants MDMA and METH dose-dependently and fully generalized to the MDPV training dose. Indeed, the $\mathrm{ED}_{50}$ values for cumulative MDPV, MDMA, and METH were virtually identical in this assay, suggesting similar potency to induce interoceptive effects across all three drugs. That the subjective effects of these drugs were so similar in the mouse may be somewhat surprising, given that MDMA (Rudnick and Wall, 1992) and METH (Rothman et al, 2001) are monoamine releasers, whereas MDPV, unlike other synthetic cathinones such as 4-MMC and methylone (Baumann et al, 2012a), is not a releaser, but a cocaine-like reuptake inhibitor (Baumann et al, 2012b; 

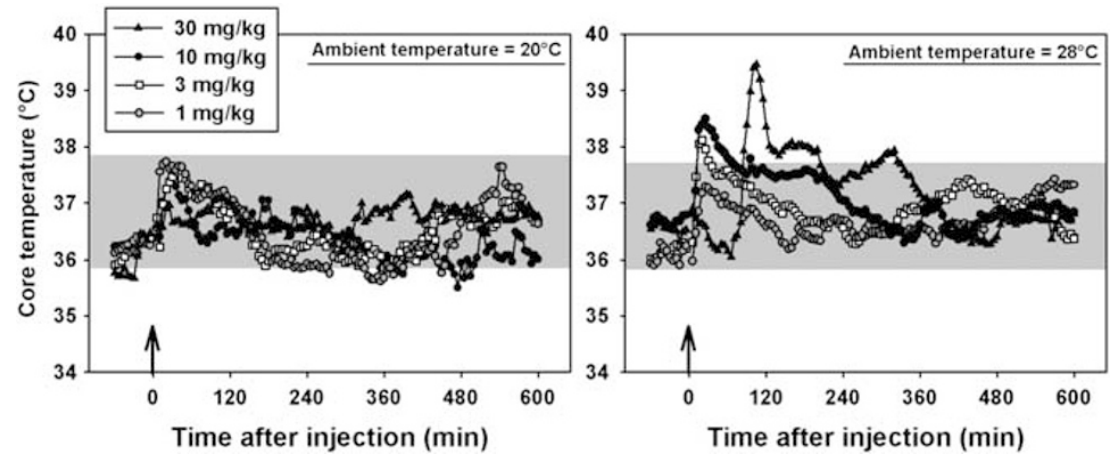

Figure 6 Effects of I (gray circles), 3 (white squares), 10 (black circles) or 30 (black triangles) mg/kg MDPV on thermoregulation when administered in either a cool (left panel) or warm (right panel) ambient environment. Shaded regions represent the range of core temperatures recorded over $24 \mathrm{~h}$ from mice treated with saline. Abscissae: points to the left of the up arrow denote baseline data before injection. Numbers refer to time, in minutes, following MDPV or MDMA administration. Ordinates: core temperature, in ${ }^{\circ} \mathrm{C}$, as measured by radiotelemetry.

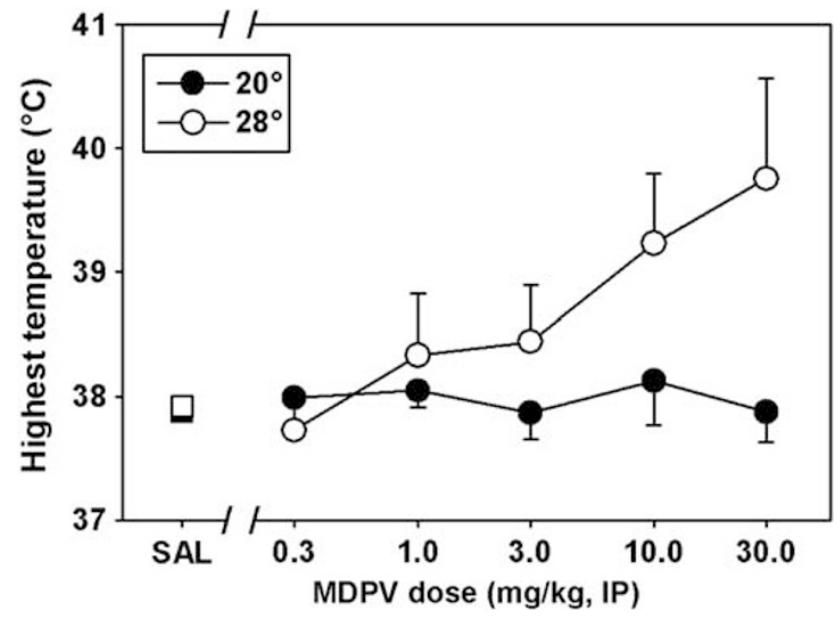

Figure 7 Maximum temperature recorded after administration of various doses of saline (squares) or MDPV (circles), measured in either a cool $20^{\circ} \mathrm{C}$ (filled) or a warm $28^{\circ} \mathrm{C}$ (unfilled) ambient environment. Abscissae: points to the left of the up arrow denote baseline data before injection. Numbers refer to time, in minutes, following MDPV or MDMA administration. Ordinates: core temperature, in ${ }^{\circ} \mathrm{C}$, as measured by radiotelemetry.

Simmler et al, 2012). However, METH has previously been shown to substitute for cocaine in mice trained to discriminate cocaine from saline (eg, Rodvelt et al, 2011), and we have previously reported that cocaine produces full generalization in mice trained to discriminate $S(+)$-MDMA or $\mathrm{R}(-)$-MDMA from saline (Murnane et al, 2009). Similarly, Johanson et al (2006) reported that humans could be trained to discriminate among $20 \mathrm{mg} \mathrm{d}$-amphetamine, $0.75 \mathrm{mg} / \mathrm{kg} \mathrm{mCPP}$ and placebo, and that when tested with 1.0 and $1.5 \mathrm{mg} / \mathrm{kg}$ MDMA, half the participants reported MDMA to be amphetamine-like and half reported it to be mCPP-like. Thus, there seems to be substantial overlap between the discriminative stimulus effects of cocaine-like reuptake blockers, amphetamine-type releasers, and MDMA. The present substitution of both MDMA and METH for the cocaine-like monoamine reuptake blocker MDPV would seem to be consistent with these previous findings. A recent study involving discriminative stimulus effects of the cathinone analogue and common 'bath salt' constituent mephedrone in the rat showed that cocaine, MDMA, and METH elicited dose-dependent mephedrone-like responding (Varner et al, 2012), although MDMA was more effective in this regard. These results are also consistent with a psychostimulant-like interoceptive effect of synthetic cathinones, and fit with an early publication investigating amphetamine-like discriminative stimulus effects of several $\mathrm{N}$-alkyl and methylenedioxysubstituted cathinone analogues in the rat (Dal Cason et al, 1997), although this report did suggest that the methylenedioxy analogues were more MDMA-like than amphetaminelike, which is perhaps not surprising.

The interoceptive effects of MDPV were dose- and time dependent in these studies. It is perhaps notable that the training dose here used- $0.3 \mathrm{mg} / \mathrm{kg}$ - engendered disparate results when administered in training sessions, when accumulated up to in substitution tests, and in time-course studies where a single bolus dose was injected. This may be because of the fact that training sessions were conducted in a very different manner than test sessions. For example, during a training session, responding on the injectionappropriate lever was reinforced, providing a salient cue to guide behavior for the remainder of the session. In contrast, during cumulative dose-substitution sessions, as well as during bolus dose time-course tests, no responses were reinforced. This likely resulted in very different states of 'behavioral momentum' (Nevin et al, 1983) for the subjects across these distinct procedures, which has previously been shown to modulate drug effects in pigeons (Poling et al, 2000; Pinkston et al, 2009) and mice (Leslie et al, 2005).

In our previous work investigating the discriminative stimulus effects of MDMA and its enantiomers, we reported that, following a bolus dose of $3.0 \mathrm{mg} / \mathrm{kg}$ MDMA, full discriminative control was observed within $10 \mathrm{~min}$ after injection and remained largely unchanged over approximately the next $50 \mathrm{~min}$, suggesting that the interoceptive effects of this dose of MDMA have a relatively rapid onset and last at least $60 \mathrm{~min}$ after injection in the mouse (Fantegrossi et al, 2009). The pattern of responding after administration of $1.0 \mathrm{mg} / \mathrm{kg}$ MDPV was quite similar, and it seems likely that a higher dose of MDPV would look very similar indeed to what we have previously seen with $3.0 \mathrm{mg} /$ $\mathrm{kg}$ MDMA. We have also reported that cumulative doses of MDMA lead to higher concentrations of MDMA in plasma, 

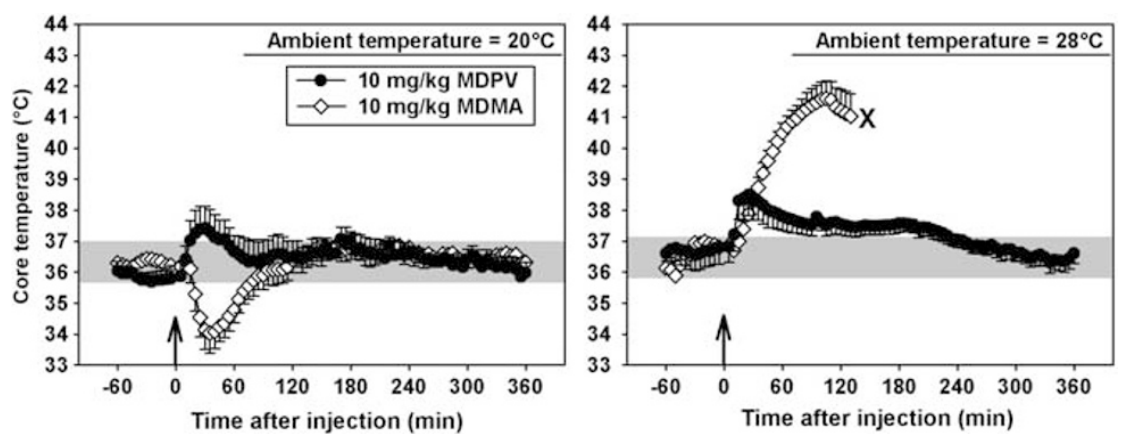

Figure 8 Effects of $10 \mathrm{mg} / \mathrm{kg}$ MDPV (black circles) or MDMA (white diamonds) on thermoregulation when administered in either a cool (left panel) or warm (right panel) ambient environment. The ' $X$ ' adjacent to the last data point obtained following administration of MDMA in the warm ambient environment denotes the approximate time that all mice were removed from the chambers and euthanized, in accordance with our IACUC protocol. Shaded regions represent the range of core temperatures recorded over $24 \mathrm{~h}$ from mice treated with saline. Abscissae: points to the left of the up arrow denote baseline data prior to injection. Numbers refer to time, in minutes, following MDPV or MDMA administration. Ordinates: core temperature, in ${ }^{\circ} \mathrm{C}$, as measured by radiotelemetry.

as compared with administration of an equivalent bolus dose, revealing that, consistent with previous studies in rats (Chu et al, 1996), squirrel monkeys (Mechan et al, 2006; Mueller et al, 2008), and humans (de la Torre et al, 2000), metabolism is also decreased when the dose is administered cumulatively in the mouse (Fantegrossi et al, 2009). Analogous studies have not yet been performed with MDPV, but it is possible that this compound also displays nonlinear pharmacokinetics, which may explain the apparent potency differences here observed when the drug was administered cumulatively, $v s$ when it was given as a single bolus dose. It is clear that more information on the basic pharmacokinetics of MDPV is necessary.

Because ambient temperature has been shown to largely affect the thermoregulatory effects of MDMA (Dafters, 1994; Malberg and Seiden, 1998)-but not to alter locomotorstimulant effects (Dafters, 1994; O'Shea et al, 2005)-we used radiotelemetry to simultaneously monitor both of these end points in response to various doses of MDPV at either 20 or $28^{\circ} \mathrm{C}$. Interestingly, we found that, in contrast to MDMA, locomotor-stimulant effects of $10 \mathrm{mg} / \mathrm{kg}$ MDPV were enhanced at the warm ambient temperature. This increase in motor activity was not due to a change in duration of drug action, but was due to MDPV eliciting absolutely greater motor activity at every time point after administration. Consistent with previous studies, we found that the locomotor effects of $10 \mathrm{mg} / \mathrm{kg}$ MDMA were essentially indistinguishable whether administered at 20 or $28^{\circ} \mathrm{C}$. The dose-effect curve for locomotor effects of MDPV at $28^{\circ} \mathrm{C}$ was biphasic, due to the induction of focused stereotypy in all subjects at the highest tested dose $(30 \mathrm{mg} / \mathrm{kg})$. Observed stereotypies included self-injurious skin-picking and chestbiting behavior that became rather severe in four out of six mice, resulting in tissue injury and bleeding. It should be noted that drug-induced self-injurious behavior in the mouse has previously been reported following high or repeated doses of a range of classical drugs, including caffeine (Mardikar et al, 1969), clonidine (Razzak et al, 1975), L-type calcium channel agonists (+ I - ) Bay K 8644 and FPL 64176 (Jinnah et al, 1999; Kasim et al, 2002), METH (Shishido et al, 2000; Kita et al, 2000), amphetamine (Wagner et al, 2004), and pemoline (Devine 2012). Nevertheless, no MDPV-induced self-injurious behavior was observed when the drug was administered at the cool $20-{ }^{\circ} \mathrm{C}$ ambient temperature, perhaps suggesting a potential role of ambient temperature in MDPV-induced selfinjurious behavior.

With regards to MDPV effects on thermoregulation, we characterized an unexpected lack of dose dependence when the drug was administered in the $20-^{\circ} \mathrm{C}$ ambient environment. At that cool ambient temperature, MDPV doses from 1 to $30 \mathrm{mg} / \mathrm{kg}$ each induced a rise in core temperature of approximately $1.5^{\circ} \mathrm{C}$, which was not different from that observed following saline administration, and the time course of this effect was also similar across all tested doses. The effects of these treatments on locomotor activity at $20^{\circ} \mathrm{C}$ were also not dose dependent, with each tested dose of MDPV inducing approximately 3.5 -fold more activity counts than saline control injections. In contrast, maximal mean core temperatures of $37.73 \pm 0.27,38.33 \pm 0.49$, $38.44 \pm 0.46,39.23 \pm 0.56$, and $39.75 \pm 0.81{ }^{\circ} \mathrm{C}$ were observed following administration of $0.3,1,3,10$, and $30 \mathrm{mg} / \mathrm{kg}$ MDPV, respectively, at an ambient temperature of $28^{\circ} \mathrm{C}$. It is not clear why dose dependency of MDPV effects should be affected by ambient temperature, and future studies designed specifically to answer this question are certainly needed.

The comparisons of $10 \mathrm{mg} / \mathrm{kg}$ MDPV and MDMA were particularly interesting. First, it should be noted that these compounds had identical $\mathrm{ED}_{50}$ values in the present drugdiscrimination experiments, and that $10 \mathrm{mg} / \mathrm{kg}$ of either compound elicited very similar locomotor responses at $20{ }^{\circ} \mathrm{C}$ (compare filled circles in the left panel of Figure 3 with filled circles in Figure 4). Based on these two findings, we might expect the thermoregularoty effects of these two compounds to also show some correspondence at this dose, however, this was far from the case. When $10 \mathrm{mg} / \mathrm{kg}$ of these drugs were administered at $20^{\circ} \mathrm{C}$, MDMA reduced core temperature by about $2{ }^{\circ} \mathrm{C}$, whereas MDPV increased core temperature by approximately $1.5^{\circ} \mathrm{C}$. When $10 \mathrm{mg} / \mathrm{kg}$ MDPV was administered at $28^{\circ} \mathrm{C}$, a similar $\sim 2.0^{\circ} \mathrm{C}$ hyperthermia was observed, suggesting that ambient temperature may not be a particularly important factor in the thermoregulatory effects of MDPV in the mouse. In contrast, when $10 \mathrm{mg} / \mathrm{kg}$ MDMA was administered at $28^{\circ} \mathrm{C}$, core temperature increased by close to $6^{\circ} \mathrm{C}$, and all mice 
had to be prematurely removed from the study and euthanized, in accordance with our IACUC protocol. In summary, these comparisons between MDPV and MDMA suggest that, although both compounds affect thermoregulation and motor activity, they likely do so through distinct mechanisms. Mechanistic studies to investigate the role of various monoamine transporters and receptors in the mediation of MDPV-induced hyperthermia and locomotor stimulation may elucidate important underlying differences between this emerging drug of abuse and more traditional psychostimulants, and may lead to clinically relevant pharmacotherapeutics useful in cases of MDPV overdose.

The presently reported studies may suggest that people recreationally using illicit 'bath salt' products might be at greater risk if their drug use occurs in a warm ambient environment. Common adverse reactions elicited by MDPV overdose in human users include agitation (perhaps analogous to locomotor-stimulant effects in mice), psychosis and violent behavior (perhaps comparable to selfinjurious behavior in mice), hyperthermia (directly observed in mice), and tachycardia (Kyle et al, 2011; Spiller et al, 2011; Borek and Holstege, 2012; Murray et al, 2012), although no studies have yet attempted to correlate symptom severity with ambient temperature. Nevertheless, based upon the present data, we might expect to observe more extreme drug effects if MDPV is administered at higher temperatures. Results from the present drugdiscrimination experiments indicate that the subjective effects of MDPV in humans may be similar to those of the more established amphetamine-like psychostimulants, and may suggest that human users of these substances may seek similar drug experiences with 'bath salt' products. As the synthetic cathinones continue to emerge as drugs of abuse, it will be critical to rapidly respond from both a scientific and regulatory perspective. It is hoped that data-both in vitro and in vivo-will continue be used to inform policy decisions regarding these interesting compounds.

\section{ACKNOWLEDGEMENTS}

We thank William S Hyatt for helpful technical assistance, and the UAMS Division of Laboratory Animal Medicine for expert husbandry services. This research was generously supported by the UAMS Center for Translational Neuroscience (RR020146) and the UAMS Translational Research Institute (RR029884). A portion of this work was supported by the Intramural Research Programs of National Institute on Drug Abuse and National Institute on Alcohol Abuse and Alcoholism. The views expressed herein are those of the authors and do not necessarily represent the views of the University of Arkansas for Medical Sciences or the National Institute on Drug Abuse.

\section{DISCLOSURE}

The authors declare no conflict of interest.

\section{Author contributions}

WEF designed and supervised the project, analyzed data, and wrote the first draft of the manuscript. KCR synthesized and analyzed the purity of MDPV. BMG and SMZ performed surgeries to implant radiotelemetry probes and carried out all drug-discrimination and telemetry experiments. All authors contributed significantly to the writing of the final version of the article.

\section{REFERENCES}

American Association of Poison Control Centers (2012): Bath Salts Data, Updated September 10, 2012. Accessed 13 September 2012 at aapcc.org/dnn/Portals/0/Bath\%20Salts\%20Data\%20for\%20Website\%208.2012\%282\%29.pdf.

Baumann MH, Ayestas MA Jr, Partilla JS, Sink JR, Shulgin AT, Daley PF et al (2012a). The designer methcathinone analogs, mephedrone and methylone, are substrates for monoamine transporters in brain tissue. Neuropsychopharmacology 37: 1192-1203.

Baumann MH, Partilla JS, Lehner KR, Thorndike EB, Hoffman AF, Holy $\mathrm{M}$ et al (2012b). Powerful cocaine-like actions of 3,4methylenedioxypyrovalerone (MDPV), a principal constituent of psychoactive 'bath salts' products. Neuropsychopharmacology doi:10.1038/npp.2012.204.

Borek HA, Holstege CP (2012). Hyperthermia and multiorgan failure after abuse of 'bath salts' containing 3,4-methylenedioxypyrovalerone. Ann Emerg Med 60: 103-105.

Chu T, Kumagai Y, DiStefano EW, Cho AK (1996). Disposition of methylenedioxymethamphetamine and three metabolites in the brains of different rat strains and their possible roles in acute serotonin depletion. Biochem Pharmacol 51: 789-796.

Dafters RI (1994). Effect of ambient temperature on hyperthermia and hyperkinesis induced by 3,4-methylenedioxymethamphetamine (MDMA or 'ecstasy') in rats. Psychopharmacology (Berl) 114: $505-508$.

Dal Cason TA, Young R, Glennon RA (1997). Cathinone: an investigation of several N-alkyl and methylenedioxy-substituted analogs. Pharmacol Biochem Behav 58: 1109-1116.

de la Torre R, Farré M, Ortuño J, Mas M, Brenneisen R, Roset PN et al (2000). Non-linear pharmacokinetics of MDMA ('ecstasy') in humans. Br J Clin Pharmacol 49: 104-109.

Devine DP (2012). The pemoline model of self-injurious behaviour. Methods Mol Biol 829: 155-163.

Fantegrossi WE, Ciullo JR, Wakabayashi KT, De La Garza R II, Traynor JR, Woods JH (2008). A comparison of the physiological, behavioral, neurochemical and microglial effects of methamphetamine and 3,4-methylenedioxymethamphetamine in the mouse. Neuroscience 151: 533-543.

Fantegrossi WE, Murai N, Mathúna BO, Pizarro N, de la Torre R (2009). Discriminative stimulus effects of 3,4-methylenedioxymethamphetamine and its enantiomers in mice: pharmacokinetic considerations. J Pharmacol Exp Ther 329: 1006-1015.

Fauquet JP, Morel E, Demarty C, Rapin JR (1976). Role of central catecholamines in the psychostimulant activity of pyrovalerone. Arch Int Pharmacodyn Ther 224: 325-337.

Fuwa T, Fukumori N, Tanaka T, Kubo Y, Ogata A, Uehara S et al (2007). Microdialysis study of drug effects on central nervous system - changes of dopamine levels in mice striatum after oral administration of methylenedioxypyrovalerone. Ann Rep Tokyo Metr Inst PH 58: 287-292.

Goldberg J, Gardos G, Cole JO (1973). A controlled evaluation of pyrovalerone in chronically fatigued volunteers. Int Pharmacopsychiatry 8: 60-69.

Granado N, Ares-Santos S, Oliva I, O'Shea E, Martin ED, Colado MI et al (2011). Dopamine D2-receptor knockout mice are protected against dopaminergic neurotoxicity induced by methamphetamine or MDMA. Neurobiol Dis 42: 391-403. 
Heron C, Costentin J, Bonnet JJ (1994). Evidence that pure uptake inhibitors including cocaine interact slowly with the dopamine neuronal carrier. Eur J Pharmacol 264: 391-398.

Holliday AR, Morris RB, Sharpley RP (1964). Compound 84/F 1983 compared with $\mathrm{D}$-amphetamine and placebo in regard to effects on human performance. Psychopharmacologia 6: 192-200.

Huang PK, Aarde SM, Angrish D, Houseknecht KL, Dickerson TJ, Taffe MA (2012). Contrasting effects of d-methamphetamine, 3,4-methylenedioxymethamphetamine, 3,4-methylenedioxypyrovalerone, and 4-methylmethcathinone on wheel activity in rats. Drug Alcohol Depend 126: 168-175.

Itzhak Y, Achat-Mendes C (2004). Methamphetamine and MDMA (ecstasy) neurotoxicity: 'of mice and men'. IUBMB Life 56: 249-255.

Itzhak Y, Anderson KL, Ali SF (2004). Differential response of nNOS knockout mice to MDMA ('ecstasy')- and methamphetamine-induced psychomotor sensitization and neurotoxicity. Ann NY Acad Sci 1025: 119-128.

Jinnah HA, Yitta S, Drew T, Kim BS, Visser JE, Rothstein JD (1999). Calcium channel activation and self-biting in mice. Proc Natl Acad Sci USA 96: 15228-15232.

Johanson CE, Kilbey M, Gatchalian K, Tancer M (2006). Discriminative stimulus effects of 3,4-methylenedioxymethamphetamine (MDMA) in humans trained to discriminate among d-amphetamine, meta-chlorophenylpiperazine and placebo. Drug Alcohol Depend 81: 27-36.

Kasim S, Egami K, Jinnah HA (2002). Self-biting induced by activation of L-type calcium channels in mice: serotonergic influences. Dev Neurosci 24: 322-327.

Kita T, Matsunari Y, Saraya T, Shimada K, O'Hara K, Kubo K et al (2000). Methamphetamine-induced striatal dopamine release, behavior changes and neurotoxicity in $\mathrm{BALB} / \mathrm{c}$ mice. Int $J$ Dev Neurosci 18: 521-530.

Kyle PB, Iverson RB, Gajagowni RG, Spencer L (2011). Illicit bath salts: not for bathing. J Miss State Med Assoc 52: 375-377.

Leonhart MM (2011). Schedules of controlled substances: temporary placement of three synthetic cathinones into schedule I. Fed Reg 76: 65371-65375.

Leslie JC, Shaw D, Gregg G, McCormick N, Reynolds DS, Dawson GR (2005). Effects of reinforcement schedule on facilitation of operant extinction by chlordiazepoxide. J Exp Anal Behav 84: 327-338.

Malberg JE, Seiden LS (1998). Small changes in ambient temperature cause large changes in 3,4-methylenedioxymethamphetamine (MDMA)-induced serotonin neurotoxicity and core body temperature in the rat. J Neurosci 18: 5086-5094.

Mann H, Ladenheim B, Hirata H, Moran TH, Cadet JL (1997). Differential toxic effects of methamphetamine (METH) and methylenedioxymethamphetamine (MDMA) in multidrug-resistant (mdr1a) knockout mice. Brain Res 769: 340-346.

Mardikar BR, Srinivasan S, Balwani JH (1969). On the phenomenon of caffeine induced automutilation. Indian J Physiol Pharmacol 13: 261-263.

Mechan A, Yuan J, Hatzidimitriou G, Irvine RJ, McCann UD, Ricaurte GA (2006). Pharmacokinetic profile of single and repeated oral doses of MDMA in squirrel monkeys: relationship to lasting effects on brain serotonin neurons. Neuropsychopharmacology 31: 339-350.

Meltzer PC, Butler D, Deschamps JR, Madras BK (2006). 1-(4Methylphenyl)-2-pyrrolidin-1-yl-pentan-1-one (pyrovalerone) analogues: a promising class of monoamine uptake inhibitors. J Med Chem 49: 1420-1432.

Mueller M, Peters FT, Maurer HH, McCann UD, Ricaurte GA (2008). Nonlinear pharmacokinetics of $(+/-) 3,4$-methylenedioxymethamphetamine (MDMA, 'Ecstasy') and its major metabolites in squirrel monkeys at plasma concentrations of MDMA that develop after typical psychoactive doses. $J$ Pharmacol Exp Ther 327: 38-44.
Murnane KS, Murai N, Howell LL, Fantegrossi WE (2009). Discriminative stimulus effects of psychostimulants and hallucinogens in $S(+)$-3,4-methylenedioxymethamphetamine (MDMA) and R(-)-MDMA trained mice. J Pharmacol Exp Ther 331: 717-723.

Murnane KS, Perrine SA, Finton BJ, Galloway MP, Howell LL, Fantegrossi WE (2012). Effect of exposure to amphetamine derivatives on passive avoidance performance and the central levels of monoamines and their metabolites in mice: correlations between behavior and neurochemistry. Psychopharmacology 220: 495-508.

Murray BL, Murphy CM, Beuhler MC (2012). Death following recreational use of designer drug 'bath salts' containing 3,4Methylenedioxypyrovalerone (MDPV). J Med Toxicol 8: 69-75.

Nevin JA, Mandell C, Atak JR (1983). The analysis of behavioral momentum. J Exp Anal Behav 39: 49-59.

O'Callaghan JP, Miller DB (1994). Neurotoxicity profiles of substituted amphetamines in the C57BL/6J mouse. J Pharmacol Exp Ther 270: 741-751.

O'Shea E, Escobedo I, Orio L, Sanchez V, Navarro M, Green AR et al (2005). Elevation of ambient room temperature has differential effects on MDMA-induced 5-HT and dopamine release in striatum and nucleus accumbens of rats. Neuropsychopharmacology 30: 1312-1323.

Panas HN, Lynch LJ, Vallender EJ, Xie Z, Chen GL, Lynn SK et al (2010). Normal thermoregulatory responses to 3-iodothyronamine, trace amines and amphetamine-like psychostimulants in trace amine associated receptor 1 knockout mice. J Neurosci Res 88: 1962-1969.

Pinkston JW, Ginsburg BC, Lamb RJ (2009). Examination of reinforcement magnitude on the pharmacological disruption of fixed-ratio performance. Exp Clin Psychopharmacol 17: 237-246.

Poling A, Byrne T, Christian L, Lesage MG (2000). Effects of cocaine and morphine under mixed-ratio schedules of food delivery: support for a behavioral momentum analysis. Pharmacol Biochem Behav 66: 313-321.

Razzak A, Fujiwara M, Ueki S (1975). Automutilation induced by clonidine in mice. Eur J Pharmacol 30: 356-359.

Rodvelt KR, Lever SZ, Lever JR, Blount LR, Fan KH, Miller DK (2011). SA 4503 attenuates cocaine-induced hyperactivity and enhances methamphetamine substitution for a cocaine discriminative stimulus. Pharmacol Biochem Behav 97: 676-682.

Ross EA, Watson M, Goldberger B (2011). "Bath salts" intoxication. $N$ Engl J Med 365: 967-968.

Rothman RB, Baumann MH, Dersch CM, Romero DV, Rice KC, Carroll FI et al (2001). Amphetamine-type central nervous system stimulants release norepinephrine more potently than they release dopamine and serotonin. Synapse 39: 32-41.

Rudnick G, Wall S (1992). The molecular mechanism of (3,4methylenedioxy-methamphetamine (MDMA)): serotonin transporters are targets for MDMA-induced serotonin release. Proc Nat Acad Sci USA 89: 1817-1821.

Shishido T, Watanabe Y, Kato K, Horikoshi R, Niwa SI (2000). Effects of dopamine, NMDA, opiate, and serotonin-related agents on acute methamphetamine-induced self-injurious behavior in mice. Pharmacol Biochem Behav 66: 579-583.

Simmler LD, Buser TA, Donzelli M, Schramm Y, Dieu LH, Huwyler J et al (2012). Pharmacological characterization of designer cathinones in vitro. $\mathrm{Br} J$ Pharmacol doi:10.1111/j.14765381.2012.02145.x.

Spiller HA, Ryan ML, Weston RG, Jansen J (2011). Clinical experience with and analytical confirmation of 'bath salts' and "legal highs" (synthetic cathinones) in the United States. Clin Toxicol 49: 499-505.

Tidjane Corera A, Do-Rego JC, Costentin J, Bonnet JJ (2001). Differential sensitivity to $\mathrm{NaCl}$ for inhibitors and substrates that 
recognize mutually exclusive binding sites on the neuronal transporter of dopamine in rat striatal membranes. Neurosci Res 39: 319-325.

US Drug Enforcement Administration, Office of Diversion Control (2011): National Forensic Laboratory Information System Special Report: Synthetic Cannabinoids and Synthetic Cathinones Reported in NFLIS, 2009-2010. Springfield, VA: U.S. Drug Enforcement Administration. Accessed 13 September 2012 at deadiversion.usdoj.gov/nflis/2010rx_synth.pdf.

Varner KJ, Daigle K, Weed PF, Lewis PB, Mahne SE, Sankaranarayanan A et al (2012). Comparison of the behavioral and cardiovascular effects of mephedrone with other drugs of abuse in rats. Psychopharmacology (Berl); e-pub ahead of print 20 November 2012.

Vaugeois JM, Bonnet JJ, Duterte-Boucher D, Costentin J (1993). In vivo occupancy of the striatal dopamine uptake complex by various inhibitors does not predict their effects on locomotion. Eur J Pharmacol 230: 195-201.

Wagner GC, Avena N, Kita T, Nakashima T, Fisher H, Halladay AK (2004). Risperidone reduction of amphetamineinduced self-injurious behavior in mice. Neuropharmacology 46: 700-708.

Watterson LR, Kufahl PR, Nemirovsky NE, Sewalia K, Grabenauer M, Thomas BF et al (2012). Potent rewarding and reinforcing effects of the synthetic cathinone 3,4-methylenedioxypyrovalerone (MDPV). Addict Biol doi:10.1111/j.1369-1600. 2012.00474.x.

Wright MJ Jr, Angrish D, Aarde SM, Barlow DJ, Buczynski MW, Creehan KM et al (2012). Effect of ambient temperature on the thermoregulatory and locomotor stimulant effects of 4-methylmethcathinone in wistar and sprague-dawley rats. PLoS One 7: e44652.

Supplementary Information accompanies the paper on the Neuropsychopharmacology website (http://www.nature.com/npp) 